IR-09-019

\title{
Demography, Education and Democracy: Global Trends and the Case of Iran
}

Wolfgang Lutz (lutz@iiasa.ac.at) Jesús Crespo Cuaresma (jesus.crespo-cuaresma@uibk.ac.at) Mohammad Jalal Abbasi-Shavazi (mabbasi@ut.ac.ir)

\section{Approved by}

Detlof von Winterfeldt (detlof@iiasa.ac.at)

Director

June 24, 2009

Interim Reports on work of the International Institute for Applied Systems Analysis receive only limited review. Views or opinions expressed herein do not necessarily represent those of the Institute, its National Member Organizations, or other organizations supporting the work. 


\section{Contents}

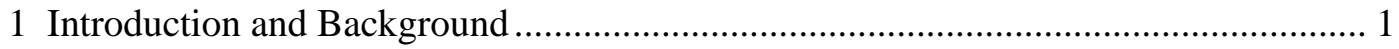

2 Population Dynamics of Improving Educational Attainment .................................... 3

3 Education and the World's Most Rapid Fertility Decline ........................................ 10

4 Global Trends in Education, Fertility Decline and Democracy ................................ 16

5 Outlook, Summary and Discussion: Female Education, Fertility Decline and Future

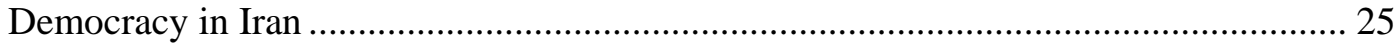

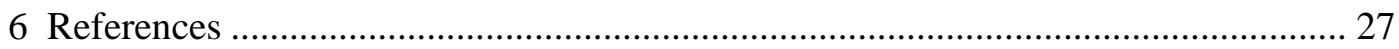




\begin{abstract}
This paper utilizes new reconstructions and projections of populations by age, sex and four levels of educational attainment for 120 countries since 1970 for a reassessment of the global relationship between improvements in human capital and democracy as measured by the Freedom House indicator of political rights. Similar to an earlier study on the effects of improving educational attainment on economic growth, the greater age detail of this new dataset can resolve earlier ambiguities about the effect of improving education as assessed on the basis of a global set of national time series. The results show consistently strong positive effects of improving overall levels of educational attainment, of a narrowing gender gap in education, and of fertility declines on improvements in the democracy indicator. This global relationship is then applied to the Islamic Republic of Iran. Over the past two decades Iran has experienced the world's most rapid fertility decline associated with massive increases in female education. The results show that based on the experience of 120 countries since 1970, Iran has a high chance of significant improvement towards more democracy over the coming years.
\end{abstract}




\section{About the Authors}

Professor Dr. Wolfgang Lutz is the Leader of the World Population Program at the International Institute for Applied Systems Analysis (IIASA); Director of the Vienna Institute of Demography (VID) of the Austrian Academy of Sciences; Professor of Social and Economic Statistics at the Vienna University of Economics and Business (WU); and Professorial Research Fellow at Oxford University.

Professor Dr. Jesús Crespo Cuaresma is Professor of Economics at the Department of Economics, University of Innsbruck, Austria; and Leader of the Project on Human Capital and Economic Growth at the International Institute for Applied Systems Analysis (IIASA).

Dr. Mohammad Jalal Abbasi-Shavazi is Associate Professor at the Department of Demography, University of Tehran, Iran; and Adjunct Fellow, Australian Demographic and Social Research Institute (ADSRI), Australian National University, Canberra. 


\title{
Demography, Education and Democracy: Global Trends and the Case of Iran
}

\author{
Wolfgang Lutz, Jesús Crespo Cuaresma, and Mohammad Jalal Abbasi-Shavazi
}

\section{Introduction and Background}

In the political science literature, there is a long tradition of studying the drivers of improvements in political rights and democracy. The so-called modernization hypothesis (see Lipset (1959) for a first systematic account of this theory) considers the level of development of a country, and in particular its educational attainment, as the main determinant of the birth and sustainability of democratic political institutions.

The theoretical arguments relating education to democracy are manifold. At the individual level, education is a determinant of political participation. As the educational level increases, individuals tend to develop a stronger sense of civic duty and a greater interest in politics. ${ }^{1}$ However, to the extent that education causes economic growth, it is an indirect determinant of democracy through the presumed link between wealth at the macroeconomic level and democracy (see Barro 1996). A further possible mechanism of influence is through the effect of female education on fertility and hence changing age structures which has been identified as a factor relevant to political stability and governance. Recent political science contributions to the theoretical literature on the link between educational attainment and democracy emphasize the increase in the benefits of political participation caused by education as the catalytic link relating changes in educational measures to changes in democracy. Glaeser et al. (2007) present a theoretical model where the effect of education on the (otherwise weak) incentives faced by individuals to support democratic regimes leads to higher stability of democratic regimes in more educated societies.

Although fertility decline is an important element of general modernization of societies, demographic changes are rarely seen as directly related to the transition to and persistence of democracy. The big exception is the literature on the "youth bulge" (see Cincotta (2008) for a recent account of the issue) which looks, however, not at the factors enhancing democracy, but rather focuses on the possible negative effects of large (male) cohorts - which are the result of past high fertility - entering young adulthood and presumably bringing instability and possibly even conflict into otherwise stable systems. In the "youth bulge" literature, it is not always clear whether such a phenomenon is only to be expected if fertility has declined recently - only this would produce a "bulge" - or whether continued high fertility would also lead to such a phenomenon. But in any case the focus of these studies is on political instability and not on democracy itself. In fact under previously authoritarian conditions, such instability of a "youth bulge" may actually lead to conditions

\footnotetext{
${ }^{1}$ Recent studies show that nonformal education also affects political participation (see Kuenzi (2006) for an empirical study about Senegal). Due to data limitations, we will refer only to formal education in the discussion.
} 
that favor the introduction of democracy. The Indonesian experience in the 1990s presents a point in case for this mechanism (see Keyfitz 1986). Since the focus of the "youth bulge" argument is quite different from our interest, we will not further refer to this literature in this paper. Instead we will consider changing age distributions as a factor closely interacting with a changing distribution of educational attainment by age and sex, and study the impacts of changes in both factors in the emergence, improvement and maintenance of democratic liberties and rights.

This paper follows an earlier one (Lutz et al. 2008) in a series of studies utilizing a newly reconstructed set of data of educational attainment distributions by sex and five-year age groups for 120 countries in the world to re-assess the macro-level returns to education. The earlier paper had a fresh look at an important long-standing macroeconomic puzzle concerning the relationship between improving educational attainment of the adult population and economic growth. While it had been established beyond reasonable doubt that at the individual level more education on average leads to higher income, previous cross-country economic growth regressions tended to show that changes in educational attainment are largely unrelated to economic growth (Barro and Lee 1996; Benhabib and Spiegel 1994; Pritchett 2001), which is in contradiction to theory and the micro-econometric evidence. Most of the literature in this field attributes the existence of this puzzle to deficiencies in the series of education and human capital data (Bloom 2006; de la Fuente and Domenech 2006; Cohen and Soto 2007). The new human capital data by age and sex, described briefly in the following section, could resolve this puzzle by providing more age detail than was previously possible. Earlier studies typically considered the entire adult population $25+$ as one age group. The average education of this huge age group is very stable and in many developing countries recent improvements in education that resulted in rapid increases of the education of the younger adult labor force - which tends to be key for economic growth in developing countries - are hardly visible in this age group which also includes the largely uneducated elderly. A consideration of education distributions by five-year age groups could easily resolve this problem and unambiguously demonstrate the consistently positive and significant effect of increasing educational attainment on economic growth.

The analysis presented in this paper uses the new age-specific dataset on human capital for cross-country panel regression in which the dependent variable is an indicator of democracy instead of economic growth. In addition, this study will also apply the estimated global level relationships to the future of one specific country which experienced astonishing social transformations over the past years and is currently at the center of international attention.

In the following we will first briefly present and discuss the new set of data by age, sex and educational attainment. Next we will look at recent demographic and education trends in Iran, the specific national illustration chosen for this paper, and discuss the interplay between female education and family planning that resulted in the world's most rapid fertility decline, bringing the total fertility rate (TFR) down from 7.0 in 1980 to 1.9 in 2006. This will be followed by a global level econometric analysis of a panel of data assessing the impacts of improving male and female education as well as declining fertility and other selected variables on changes of the chosen indicator of democratic rights. We will conclude by discussing the implications for the likely future of democracy in Iran when applying the parameters estimated from the global analysis to population projections by age, sex and level of education in Iran. 


\section{Population Dynamics of Improving Educational Attainment}

Demographers tend to study most phenomena by age and sex. But there are other human characteristics that show great discriminatory power in explaining differential trends and for which good statistical information is available. Education is a prime candidate; it has been shown that explicitly considering education as a source of observed heterogeneity can add greatly to understanding the forces driving changes in the population. When limiting the scope to demographic phenomena, both fertility and mortality are greatly influenced by education. The discriminatory power of educational categories as well as the overall influence of education on demographic trends is so pervasive that in a contribution entitled "Demographic dimensions in forecasting: Adding education to age and sex," Lutz et al. (1999) suggested to give education a status in demography that comes near to that of age and sex. As the following description will show, the often raised counterargument, that not enough systematic information was available for education as compared to age and sex, does not hold. For virtually every country in the world there is enough information from censuses and surveys to study the changing educational structure of the population by age and sex. In terms of vital events, surveys provide almost complete information on fertility by level of education (which is the most important for population dynamics) while the situation is more difficult for mortality. It is quite unsatisfactory for migration where often the information by age and sex is also lacking. But the collection of demographic information in the future will be driven by what demographic scholars and subsequently administrators in official statistics consider information that is worthwhile to be collected. In that sense, illustrating the models of population dynamics by level of education and demonstrating the overriding importance of education will pose an incentive for collecting still better information in the future.

Following this principle, the International Institute for Applied Systems Analysis (IIASA), in collaboration with the Vienna Institute of Demography (VID) of the Austrian Academy of Sciences, has recently produced a unique new dataset which applies demographic multi-state projection techniques to reconstruct the population by age, sex and level of educational attainment from empirical data from around 2000 back to 1970 in five-year steps. This has been done for 120 countries, including Iran. While a comprehensive description of methods and results is given in Lutz et al. (2007), in the following section we will provide only a brief outline of the approach and highlight the results for Iran. The same multi-state approach has recently been applied to project the population by levels of educational attainment to 2030 for all countries in the world (KC et al. 2008), and the results for Iran are included here.

At any point in time the distribution of the population by age, sex and level of educational attainment reflects the history of changes in the proportions of a cohort that attended school and reached certain educational levels. Since formal education typically happens in childhood and youth, the current educational attainment distribution of 50-54 year old women, for instance, reflects education conditions and school enrolment of more than 30 years ago. This is clearly visible in Figure 1, which shows the educational age pyramid of Iran around 2000. The figure gives the usual age pyramid with men on the left and women on the right, where shadings indicate a further subdivision for each age group of men and women by highest level of educational attainment. The picture clearly indicates that younger Iranians are not only much more numerous (due to the history of very high fertility), but also on average much better educated than older ones. This recent improvement in educational attainment is particularly impressive for women. While more than two-thirds of the young women in Iran today have completed at least junior secondary education, among their mothers' generation only a tiny fraction did so. Hence, the history of rapidly increasing education over time is well reflected in today's age pattern of education. 


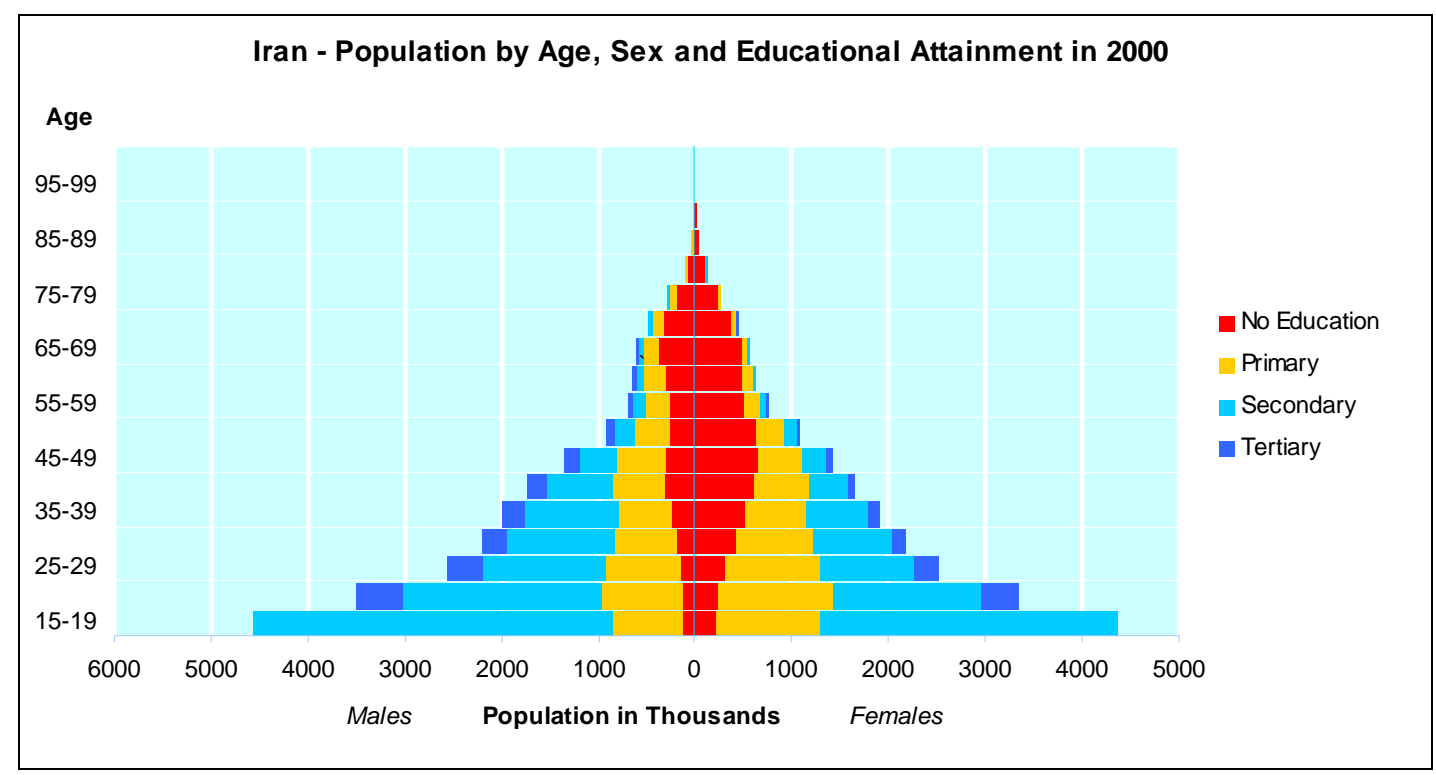

Figure 1. Age and education pyramid for Iran, 2000.

The back-projection exercise described here utilizes the fact that much of a population's education history is still reflected in its current structure. It goes back along cohort lines in five-year steps by deriving, e.g., the proportion without any formal schooling among 50-54 year old women in 1995 from that of 55-59 year olds in 2000 (see Figure 2 for the pyramid corresponding to 1970). There are only three possible factors that can cause these two proportions to differ: differential mortality, differential migration, and women who still acquire formal education after the age of 55. While such late educational transitions are typically irrelevant, differential mortality is a major issue because there is strong evidence in virtually all countries where such data exist that higher educational groups have significantly lower levels of mortality, presumably through better access to information, healthier lifestyles and better economic standing. Although this issue is mentioned in the economic literature of education data, it is not explicitly dealt with in earlier attempts of reconstructing human capital data (Barro and Lee 1996; Benhabib and Spiegel 1994). Only demographic multi-state methods can appropriately deal with differential vital rates. 


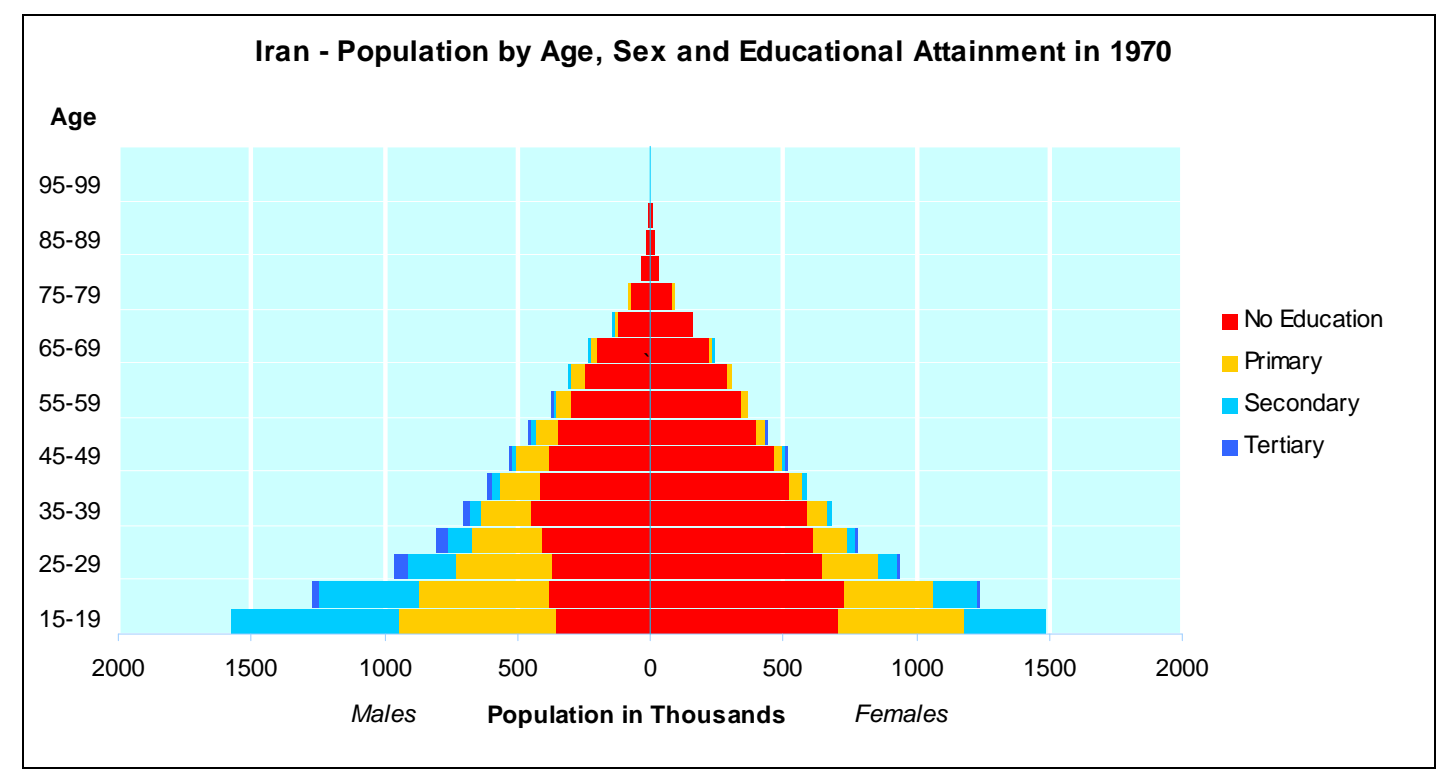

Figure 2. Reconstructed age and education pyramid for Iran, 1970.

Lutz et al. (2007) provide a detailed account of all the specific assumptions that had to be made as part of this reconstruction exercise, discuss their plausibility, and provide sensitivity analyses. The method can be summarized as follows: First, for every country, an empirical distribution of the population by age, sex and four categories of educational attainment (no formal education, some primary, completed lower secondary, completed first level of tertiary) was retrieved for a year close to 2000. In the case of Iran, the data were taken from the 1996 census and projected forward to 2000. Second, we drew on an existing United Nations (2005) dataset which provides estimates of the age and sex structure in five-year intervals since 1950 for every country in the world. For this reason our effort did not have to reconstruct the absolute sizes of the populations by individual age groups, but only the proportions with different education levels in each age group of men and women. This also made the necessary demographic assumptions a lot easier, since it was not necessary to estimate the overall level of mortality or the total volume of migration (which is implicit in the UN estimates), but only to consider to what degree these demographic forces differed by level of education. While for migration the default assumption was that it did not contribute to changing the educational composition of the population, for mortality we assumed a consistent pattern that life expectancy at age 15 differs by five years between the lowest and the highest educational category (with the difference between no education and some primary being one year and the other differences being two years each). This assumption was based on an assessment of a selection of countries from different parts of the world for which such data exist (see Lutz et al. 2007).

A further problem arose from the fact that in the empirical data, the oldest age group is typically an open-ended category such as $65^{+}$or $70+$. When going back along cohort lines, those aged $70+$ in 2000 are $40+$ in 1970. To get information for the closed intervals 40-44 to 60-64, we need to make assumptions about the distributions across age and education categories in these open intervals which were based (unless empirical information was available) on exponential trend extrapolation of the proportions in the adjacent closed age groups. This source of uncertainty is the reason why it was decided to stop the reconstruction in 1970 and not go back further into history, as the assumptions would have become progressively more restrictive. Another set of assumptions referred to the ages at which 
transitions from one educational category to another were made. Since the reconstruction is only performed for the population above age 15, this only concerned transitions to tertiary and to a lesser extent to the secondary level. Lutz et al. (2007) provide further technical details on the reconstruction of the dataset.

Table 1 provides the numerical output for the reconstruction for Iran. It shows the absolute numbers of men and women by five-year age groups and the four levels of educational attainment for Iran for 1970, 2000 and 2030. The bottom line of each sub-table gives the distribution across educational categories for all adult age groups together; the righthand margin gives the summary measure of the average level of education for individual age groups in the form of mean years of schooling. Although the estimation of this indicator requires additional assumptions in terms of the average years of schooling it takes to become a member of a certain educational attainment category, it was decided to provide it in order to facilitate a comparison to other datasets that only provide mean years of schooling. Finally, the number in the lower right corner of each matrix gives the mean year of schooling for the entire adult population above age 25. This is the number most frequently used in economic studies. Although most often used by economists, this single number has only limited information content. It not only obscures the distribution across educational categories but also hides inter-cohort changes such as the significant improvement in the educational level of younger Iranian women. Having the full matrix available significantly expands the possibility for analysis not only along the age dimension but also with respect to different mixes of primary, secondary and tertiary education in the population. 
Table 1. Results of the reconstructions and projections of the population by age, sex and level of educational attainment plus mean years of schooling (MYS), Iran, 1970, 2000 and 2030 (in thousands). Sources: Lutz et al. (2007); KC et al. (2008).

\begin{tabular}{|c|c|c|c|c|c|c|c|c|c|c|}
\hline \multirow[t]{2}{*}{ Age groups } & \multicolumn{5}{|c|}{ Males } & \multicolumn{5}{|c|}{ Females } \\
\hline & No education & Primary & Secondary & Tertiary & MYS & No education & Primary & Secondary & Tertiary & MYS \\
\hline \multicolumn{11}{|l|}{ In 1970} \\
\hline $15-19$ & 360.9 & 585.3 & 627.8 & 0.0 & 6.1 & 703.3 & 478.1 & 303.9 & 0.0 & 3.7 \\
\hline $20-24$ & 380.5 & 492.6 & 368.2 & 28.3 & 5.3 & 732.7 & 328.9 & 163.0 & 8.2 & 2.8 \\
\hline $25-29$ & 375.3 & 358.9 & 180.6 & 51.2 & 4.7 & 648.5 & 202.4 & 76.4 & 12.3 & 2.1 \\
\hline $30-34$ & 407.7 & 268.6 & 84.2 & 41.7 & 3.6 & 612.8 & 124.5 & 34.2 & 8.0 & 1.4 \\
\hline $35-39$ & 446.4 & 191.1 & 44.6 & 22.6 & 2.5 & 586.5 & 75.0 & 16.9 & 3.7 & 0.9 \\
\hline $40-44$ & 416.2 & 152.1 & 30.3 & 14.5 & 2.1 & 520.8 & 54.5 & 12.5 & 2.0 & 0.7 \\
\hline $45-49$ & 384.7 & 119.2 & 20.1 & 9.0 & 1.7 & 461.3 & 39.4 & 8.9 & 1.0 & 0.6 \\
\hline $50-54$ & 344.8 & 89.9 & 12.8 & 5.3 & 1.4 & 401.5 & 27.8 & 6.2 & 0.5 & 0.5 \\
\hline $55-59$ & 295.7 & 64.5 & 7.7 & 3.0 & 1.2 & 343.3 & 19.3 & 4.1 & 0.3 & 0.4 \\
\hline $60-64$ & 252.5 & 45.9 & 4.6 & 1.6 & 0.9 & 293.2 & 13.3 & 2.8 & 0.1 & 0.3 \\
\hline $65+$ & 440.9 & 58.3 & 4.4 & 1.4 & 0.7 & 521.2 & 16.4 & 3.1 & 0.1 & 0.2 \\
\hline $15+$ & 4105.6 & 2426.6 & 1385.5 & 178.6 & 3.6 & 5825.1 & 1379.5 & 632.1 & 36.2 & 1.8 \\
\hline $25+$ & 3364.2 & 1348.6 & 389.4 & 150.3 & 2.5 & 4389.1 & 572.5 & 165.1 & 28.1 & 1.0 \\
\hline \multicolumn{11}{|l|}{ In 2000} \\
\hline $15-19$ & 119.3 & 726.3 & 3702.1 & 0.0 & 8.7 & 209.6 & 1059.4 & 3073.0 & 0.0 & 8.0 \\
\hline $20-24$ & 133.1 & 835.0 & 2032.3 & 495.5 & 9.1 & 248.6 & 1166.8 & 1529.4 & 396.1 & 7.9 \\
\hline $25-29$ & 148.0 & 765.5 & 1283.5 & 369.2 & 8.6 & 317.8 & 972.6 & 979.6 & 236.2 & 7.0 \\
\hline $30-34$ & 181.6 & 643.6 & 1113.0 & 268.1 & 8.2 & 416.2 & 809.2 & 806.6 & 138.5 & 6.2 \\
\hline $35-39$ & 231.5 & 558.5 & 969.7 & 234.4 & 7.9 & 508.0 & 643.4 & 643.8 & 110.9 & 5.6 \\
\hline
\end{tabular}




\begin{tabular}{|c|c|c|c|c|c|c|c|c|c|c|}
\hline $40-44$ & 301.7 & 557.9 & 680.9 & 191.7 & 7.3 & 603.6 & 562.5 & 410.1 & 74.5 & 4.8 \\
\hline $45-49$ & 302.4 & 498.5 & 390.3 & 163.7 & 6.9 & 659.7 & 455.3 & 236.0 & 62.7 & 4.0 \\
\hline $50-54$ & 268.5 & 354.6 & 200.8 & 97.9 & 6.0 & 636.8 & 290.9 & 122.7 & 34.5 & 3.0 \\
\hline $55-59$ & 263.6 & 258.2 & 116.6 & 60.1 & 5.0 & 513.7 & 163.5 & 58.9 & 16.0 & 2.2 \\
\hline $60-64$ & 315.9 & 214.4 & 71.1 & 37.0 & 3.8 & 493.5 & 102.6 & 29.5 & 7.2 & 1.4 \\
\hline $65+$ & 1009.8 & 386.9 & 86.3 & 45.4 & 2.3 & 1239.6 & 135.9 & 33.2 & 6.2 & 0.8 \\
\hline $15+$ & 3275.3 & 5799.4 & 10646.6 & 1963.0 & 7.6 & 5846.9 & 6362.0 & 7922.7 & 1082.9 & 5.8 \\
\hline $25+$ & 3022.9 & 4238.0 & 4912.2 & 1467.5 & 6.8 & 5388.7 & 4135.9 & 3320.3 & 686.8 & 4.6 \\
\hline \multicolumn{11}{|c|}{ In 2030} \\
\hline $15-19$ & 9.3 & 381.0 & 3373.8 & 0.0 & 9.3 & 5.9 & 422.6 & 3168.6 & 0.0 & 9.2 \\
\hline $20-24$ & 15.1 & 416.3 & 2330.8 & 777.3 & 10.8 & 13.6 & 488.2 & 2298.0 & 589.2 & 10.3 \\
\hline $25-29$ & 20.2 & 405.1 & 1956.9 & 615.0 & 10.5 & 23.0 & 498.3 & 1910.3 & 444.4 & 9.9 \\
\hline $30-34$ & 28.4 & 435.0 & 1821.5 & 540.9 & 10.3 & 37.9 & 556.4 & 1569.7 & 549.8 & 10.0 \\
\hline $35-39$ & 56.5 & 690.2 & 2513.9 & 708.4 & 10.0 & 85.1 & 911.4 & 2093.1 & 720.7 & 9.6 \\
\hline $40-44$ & 84.3 & 844.1 & 2681.8 & 720.1 & 9.9 & 139.5 & 1148.5 & 2144.3 & 735.3 & 9.4 \\
\hline $45-49$ & 108.5 & 913.5 & 2538.4 & 652.7 & 10.2 & 194.9 & 1283.9 & 1937.7 & 672.9 & 9.4 \\
\hline $50-54$ & 117.5 & 745.6 & 1848.8 & 458.5 & 10.1 & 226.9 & 1073.5 & 1324.8 & 476.5 & 9.0 \\
\hline $55-59$ & 124.0 & 652.8 & 1156.1 & 303.7 & 9.4 & 282.1 & 874.0 & 793.2 & 327.7 & 8.1 \\
\hline $60-64$ & 139.6 & 508.7 & 923.3 & 231.5 & 9.2 & 354.8 & 702.8 & 723.4 & 127.6 & 7.0 \\
\hline $65+$ & 534.3 & 1053.3 & 1452.3 & 468.5 & 8.3 & 1543.6 & 1362.0 & 1113.5 & 236.2 & 5.3 \\
\hline $15+$ & 1237.6 & 7045.7 & 22597.6 & 5476.6 & 9.9 & 2907.4 & 9321.6 & 19076.6 & 4880.1 & 8.9 \\
\hline $25+$ & 1213.2 & 6248.3 & 16893.0 & 4699.3 & 9.8 & 2887.8 & 8410.7 & 13610.0 & 4291.0 & 8.6 \\
\hline
\end{tabular}


The methods of multi-state population dynamics can also be used to simultaneously project a population by different levels of educational attainment. Unlike for the case of multi-state reconstructions, where differential fertility need not be of concern because cohort sizes are empirically given, for the projections one needs to make assumptions about the future trends in education-specific fertility rates. In the context of the global education projections produced by IIASA (KC et al. 2008), this is done by assuming overall fertility levels together with constant relative fertility differentials among education groups. For these projections several alternative scenarios were defined both with respect to the future overall levels of fertility as well as for the future educational transition rates from lower to higher educational categories. In the following illustrations for Iran we will focus only on the so-called "UN Scenario" which defines education-specific fertility and mortality rates in such a way that it replicates the overall fertility and mortality rates of the medium variant of the UN population projections. This implies that the education pyramid given in Figure 3 has an identical overall shape to the one resulting from the UN medium variant, and only the age- and sex-specific proportions with different levels of educational attainment have been added as additional pieces of information. For the age- and sex-specific probabilities of transitions to higher educational categories, the projections presented here follow the socalled global education trend (GT) scenario. This scenario assumes that over the coming years every country follows the trend that has been observed by all 120 countries over the past two decades. This is done separately for primary, secondary and tertiary education with each country starting the future trend for its young cohorts from its current position and then following the average trends of the countries that are already somewhat more advanced in their education process.

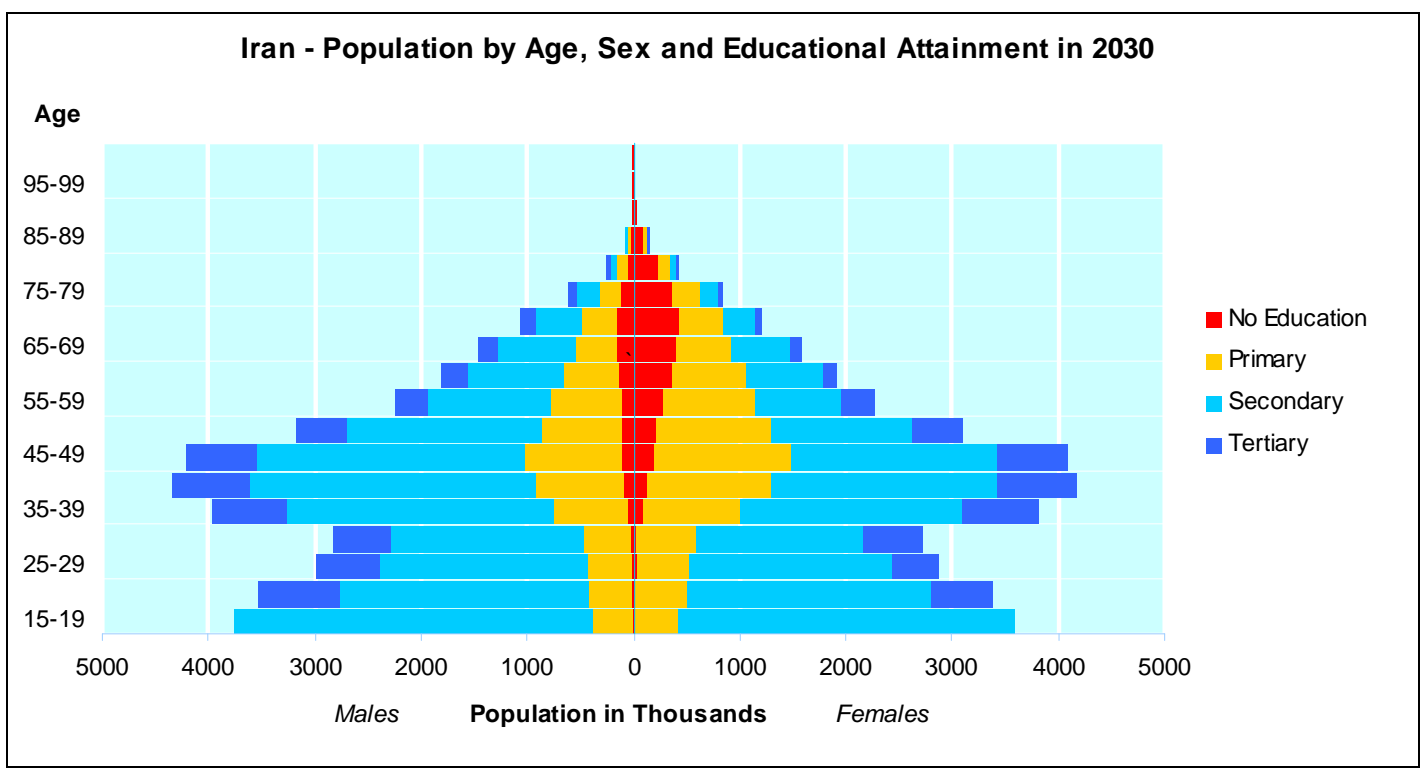

Figure 3. Projected age and education pyramid for Iran, 2030.

Figure 3 conveys the educational structure of a highly developed industrialized country for Iran in 2030, with high proportions of the population having secondary or 
higher education. Particularly among younger adults in 2030 there will be virtually no uneducated persons left and only a few will remain with primary school as their highest attainment (see also Table 1). The overall shape of the age pyramid is rather unusual as a consequence of the very large cohorts that were born in the 1980s and who will be 40 50 years old in 2030. This big cohort will dominate the age structure of Iran for the decades to come. Actually, the reduction in cohort size will make it more likely for the young generation in Iran to receive more education than implied by the GT scenario, which is only defined in terms of proportions and does not consider the changing relative size of the youngest cohorts.

But cohort size can be assumed to matter for school enrolment rates. Due to still very high fertility, some African countries will have serious problems in even maintaining current school enrolment sizes. As the school age population increases rapidly, it will be even more challenging to expand enrolment rates according to the GT scenario. For Iran, however, the picture looks very different. Once the larger absolute number of children of the huge cohorts born during the 1980s has gone through school, the number of school age children will decline rapidly as a consequence of low fertility together with declining numbers of potential mothers. In all likelihood, this will result in significant further improvements of the numbers of children with secondary and in particular tertiary education. Hence, the projection presented here is likely to be an underestimation of future educational attainment in Iran. Depending on the level of fertility in the near future this decline in the school age population will be followed by some echo effect of children born to the large cohorts.

\section{Education and the World's Most Rapid Fertility Decline}

In demography it is very common to associate changes in the education levels of women with changes in fertility levels. It is so conventional, in fact, that education plays a role in almost all theoretical approaches to the fertility transition. Education is said to provide access to modern ways of thinking, to provide the confidence to engage in the modern world, to reduce infant and child mortality, to stimulate higher levels of gender equity within couple relationships, and to promote labor force participation of women in the cash economy, hence raising the opportunity cost of having children. The education of women may also lead to a greater emphasis on their part on the 'quality' of children as opposed to the quantity of children. Finally, education is a broad indicator of societal modernization (Lucas and Meyer 1994; Kasarda et al. 1986). According to Cochrane (1979), women's education is likely to raise the age at marriage and, in some countries, to reduce the probability of ever marrying. Cochrane (1979) noted that education is positively related to more favorable attitudes towards birth control, a greater knowledge of contraception, and husband-wife communication. Caldwell (1982) stated that education influences fertility by a) reducing the benefits from children's work, b) increasing the costs of children, c) increasing the importance of the investment nature of children, d) speeding cultural change, and e) propagating Western middle-class values. As education levels increase, the educated woman is very likely to be married to an educated man and to be living in an educated society. This factor also seems to be particularly relevant for Iran (Abbasi-Shavazi et al. 2003).

Education can be divided broadly into formal (through schooling) and informal (acquiring knowledge from various sources, including media, face to face contacts, etc). 
In Iran one of the main social changes in the 20th century and particularly over the past three decades has been the expansion of mass (formal) education. The literacy rate has increased dramatically in both urban and rural areas (Table 2). For example, the literacy rate for women aged 15-19 in urban areas increased from around 57 percent in 1966 to around 97 percent (almost universal) in 1996. The improvement in rural areas has been even more dramatic, increasing from only 5 percent in 1966 to 86 percent in 1996. In 2006, around 98 percent of the women aged 20-24 and 96 percent of the women aged 25-29 in urban areas were literate as compared to 90 and 84 percent in rural areas, respectively.

Table 2. The literacy rate for women aged 15-19 to 25-29, Iran, by rural and urban areas. Sources: Statistical Centre of Iran; various censuses.

\begin{tabular}{ccccccccccc}
\hline $\begin{array}{c}\text { Age } \\
\text { groups }\end{array}$ & \multicolumn{2}{c}{1966} & \multicolumn{2}{c}{1976} & \multicolumn{2}{c}{1986} & \multicolumn{2}{c}{1996} & \multicolumn{2}{c}{2006} \\
\hline & Urban & Rural & Urban & Rural & Urban & Rural & Urban & Rural & Urban & Rural \\
$15-19$ & 57.7 & 5.4 & 75.4 & 19.8 & 85.8 & 53.0 & 96.9 & 86.4 & 98.3 & 93.2 \\
$20-24$ & 41.2 & 2.7 & 59.4 & 10.1 & 75.8 & 36.5 & 93.8 & 77.9 & 97.9 & 90.5 \\
$25-29$ & 29.5 & 1.4 & 49.4 & 4.9 & 65.5 & 22.0 & 89.5 & 65.4 & 96.3 & 84.1 \\
\hline
\end{tabular}

In 1998, around 52 percent of those admitted to government universities were girls. The figure increased to 57 percent in 1999 and then to around 65 percent in 2007. These increases in educational attainment for Iranian girls mean that marriage and childbearing are often delayed. Studies suggest that aspirations and expectations of women in post-revolutionary Iran have also risen considerably (Shadi-Talab 2005; Abdollahyan 2004; Mir-Hosseini 2002; Kian-Thiebaut 2002). This has led to the improvement of the status of women at least within the family, and women have increased their role in family decision making. Increased literacy has contributed to women's confidence and has increased women's perceptions that they have options in many aspects of their lives, particularly women in rural areas who had been much constrained by past gender inequities (Hoodfar 1996). Maternal education has also contributed to the reduction of infant mortality (Caldwell 1989; Cleland 1990), a factor which is conducive to higher child survival, and thus, reduces the demand for children.

In addition to formal schooling, informal education and knowledge transmission have indirectly contributed to the reduction of fertility in Iran. The legitimization of family planning in post-revolutionary Iran paved the way for printing family planning brochures, teaching population education in high schools, holding workshops for young couples and other educational campaigns by the mass media. By 1996, the majority of rural communities had access to piped water, electricity, TV and radio (Abbasi-Shavazi 2000), thus providing them with more information to increase their knowledge. The Literacy Movement was an organization created after the Revolution that aimed to instruct all illiterates above 10 years of age. The organization began its task in 1979 by dispatching volunteer school graduates as teachers to the villages. There were also 
classes to instruct illiterate employees under 50 working in government offices, factories and workshops. The establishment of a health network system and health houses in rural areas diffused the idea of small family size and family planning. The system employed local men and women as health officers, Behvarz, who have had regular face-to-face contacts with women of childbearing ages to provide them with family planning information and services. The compulsory pre-marriage counseling was another way by which newly married couples have been able to gain information on contraceptives, STDs, and other issues related to maternal and child health care (Hosseini-Chavoshi 2007; Salehi-Isfahani et al. 2009). In this paper, our main focus is on the impact of formal education and the expansion of schooling on fertility decline in Iran.

Studies reveal that the changes in fertility in Iran during the late 1960s and early 1970s have been small. The TFR decreased from above 7.0 in 1966 (Amani 1970, 1996; Aghajanian and Mehryar 1999; Ladier-Fouladi 1997) to around 6.5 in 1976 (Mirzaie 2005). Due to socio-political changes as well as the revolutionary protests during the years preceding the 1979 Islamic Revolution, like many other government activities, the family planning program became inactive during the years 1977 to 1979 . The TFR rose to 7.0 by 1980 . However, Iran has experienced a phenomenal fall in fertility since the mid-1980s. The TFR declined from 7.0 in 1980 to around 5.6 in 1988. The decline of fertility was slow until the new family planning program was officially inaugurated in 1989. The TFR fell sharply as of that time, dropping from around 5.6 in 1988 to around 2.8 in 1996, and to 2.2 in 2000 (Abbasi-Shavazi and McDonald 2006). Recent estimates of fertility indicate that the TFR declined to around 1.9 in 2006 (Abbasi-Shavazi et al. Forthcoming).

The sharp fall of fertility in Iran since the mid-1980s deserves international attention. That the decline occurred in an Islamic country is remarkable, particularly considering the socio-political context in Iran during and after the Islamic Revolution. Indeed, the decline of fertility (after the rise during the 1979 Islamic Revolution) started in the mid-1980s when there was no population or family planning policy. However, the decline accelerated with the reinstatement of the family planning program in 1989.

The similarity of the transition in both urban and rural areas is one of the main features of the fertility transition in Iran. There was a considerable gap between the fertility in rural and urban areas, but the TFR in both rural and urban areas continued to decline by the mid-1990s, and the gap has narrowed substantially. In 1980, the TFR in rural areas was 8.4 while that of urban areas was 5.6. In other words, there was a gap of 2.8 children between rural and urban areas. In 2006, the TFR in rural and urban areas was 2.1 and 1.8, respectively (a difference of only 0.3 children).

In addition to the direct impacts of (strictly voluntary) family planning services, government policies, such as the extension of public education particularly for girls, the establishment of the health network system (Salehi-Isfahani et al. 2009), and the increase in access to electricity and safe water, transport and communication in remote areas of Iran, most likely had an indirect effect on fertility decline. Abbasi-Shavazi and McDonald (2006) have suggested that education has been an important factor in fertility decline in Iran. The advancement of female education has affected the delay of marriage and childbearing. High aspirations and investments by families in their children's schooling are also likely to have affected couples' fertility decision making. Abbasi- 
Shavazi et al. (2008a) recently conducted a comprehensive study on the role of education on the Iranian fertility decline from which this section partly draws.

Data on fertility differentials by education in the 1970s are limited. The Iran Fertility Survey (IFS) is one of the main studies that provide information on fertility and childbearing in the 1970s (see Aghajanian et al. 1992). The IFS results indicate that there were educational differences in all age groups (Agha 1985). For example, of women aged 25-34, illiterate women had considerably higher children ever born (4.6) than women with other levels of education: primary (3.6), secondary (2.2), and diploma and higher (1.3). In the same age group, there was a significant gap (3.3 children) between illiterate women and those with diploma and higher. On average women aged 35-39 had around 6.3 children ever born at the time of the 1976 IFS. As will be discussed below, the IDHS shows that educational differences persisted to 2000. Illiterate women aged 25-34 had on average 3.7 children, as compared to 1.4 for those with diploma and higher education. The results also show that children ever born for all levels of education at different age groups decreased from 1976 to 2000, except for women aged 35-39 at the latter educational levels (secondary, diploma and higher). This is in part due to the educational composition of the population in 2000, as the majority of rural women who had higher fertility in the 1970s attained higher levels of education by 2000. Although the level of education for the general population has increased, some women may have retained aspects of their cultural beliefs about high fertility rather than adopting the views of their new educational category. A similar result was found by Abbasi-Shavazi et al. (2008b) with regard to the higher prevalence of consanguinity among the more educated women in four provinces of Iran.

In the following we will study age-specific fertility rates and total fertility rates for the periods 1986 and 2000 based on the own-children estimates of fertility using the Iran Demographic Health Survey (IDHS) (see Ministry of Health and Medical Education 2000). Figure 4 shows the trend of total fertility rates from 1986 to 2000 by educational categories as well as the trend for Iran as a whole. The results indicate that there have been significant differences in fertility by level of education in the mid1980s. For example, illiterate women in 1986 had around 7.3 children, while women with primary level education had around 6.2 children. The TFR for women with secondary and high-school levels of education was around 5.1, while women with diploma and higher had on average 3.8 children. On average, illiterate women had 3.5 children more than those with diploma and higher levels of education.

Figure 4 illustrates the downward trend for education-specific fertility rates over the 1986-2000 period. The pace of decline during the first four years (1986-1989) was slow, but it accelerated afterwards due to the revival of the family planning program in 1989. The decline continued for illiterate women and other educational categories until 2000, but the level of TFR for women with the highest category of education declined to the lowest level in 1997, and there was a slight upward trend during 1997-2000. This trend may have partly been due to the tempo effects as women in this category first postponed marriage and childbearing to continue their education and then did not postpone any further which would reduce the depressing tempo effect and result in a recovery of period TFR. By 2000 the gap between the levels of fertility for all categories of education narrowed significantly. There was only a difference of 1.2 children between the TFR for women with diploma and higher (1.8 children) and those who were illiterate (3.8 children). The level of TFR for women with secondary and high 
school (1.9) was relatively similar to that of women with diploma and higher (1.8). However, there was a significant gap (0.8) between the TFR for illiterate women and those with a primary level of education. But by 2000 illiterate women of reproductive age have become a very small and select group, mostly in remote rural areas.

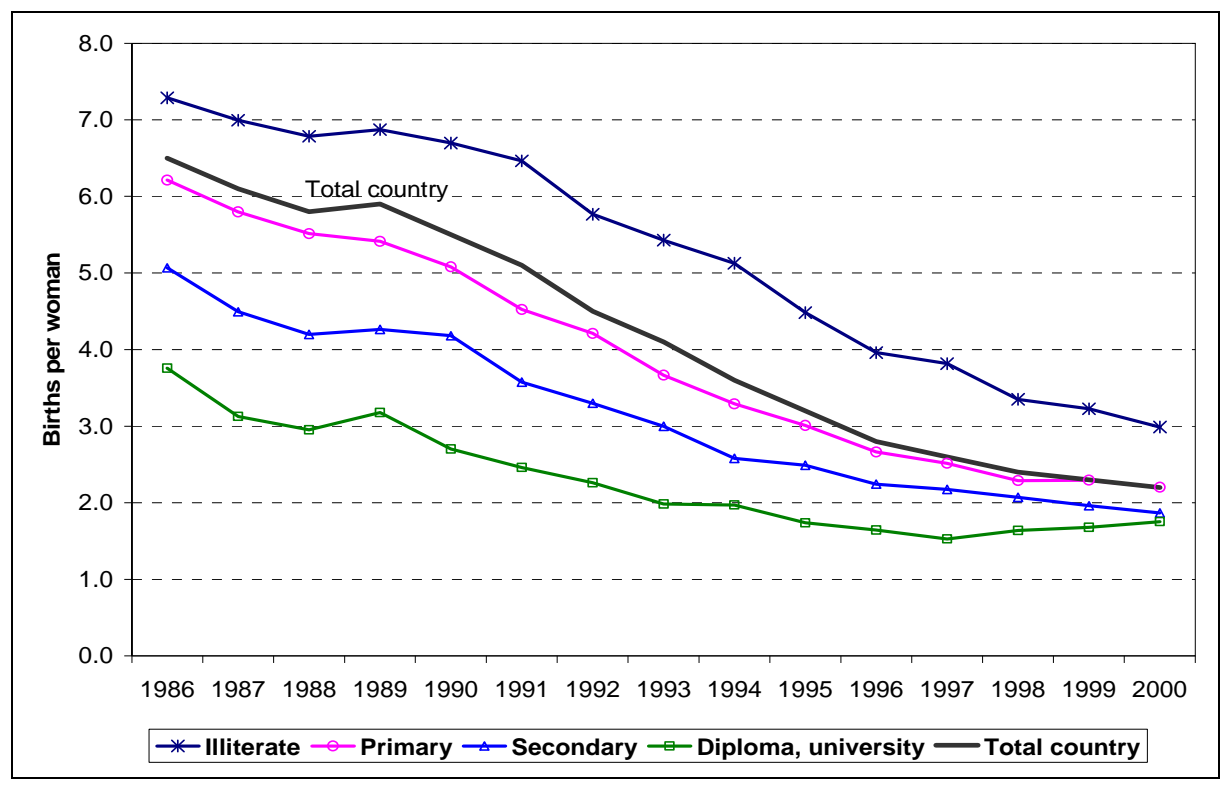

Figure 4. Own-children estimates of TFR by level of education during 1986-2000. The figures are estimated from the IDHS using the own-children method.

The age pattern of fertility by level of education during the three five-year periods, 1986-1990, 1991-1995, and 1996-2000, is illustrated in Figure 5. As discussed earlier, the level of fertility varied considerably by level of education during the first five-year period, but the gap was reduced substantially by the third period. The age pattern for women who were illiterate and for those with primary and second levels of education was indicative of a relatively early childbearing. The peak of childbearing for women of all educational categories except those with diploma and higher was observed in age group 20-24, and as expected, women with diploma and higher had a delayed childbearing pattern. 


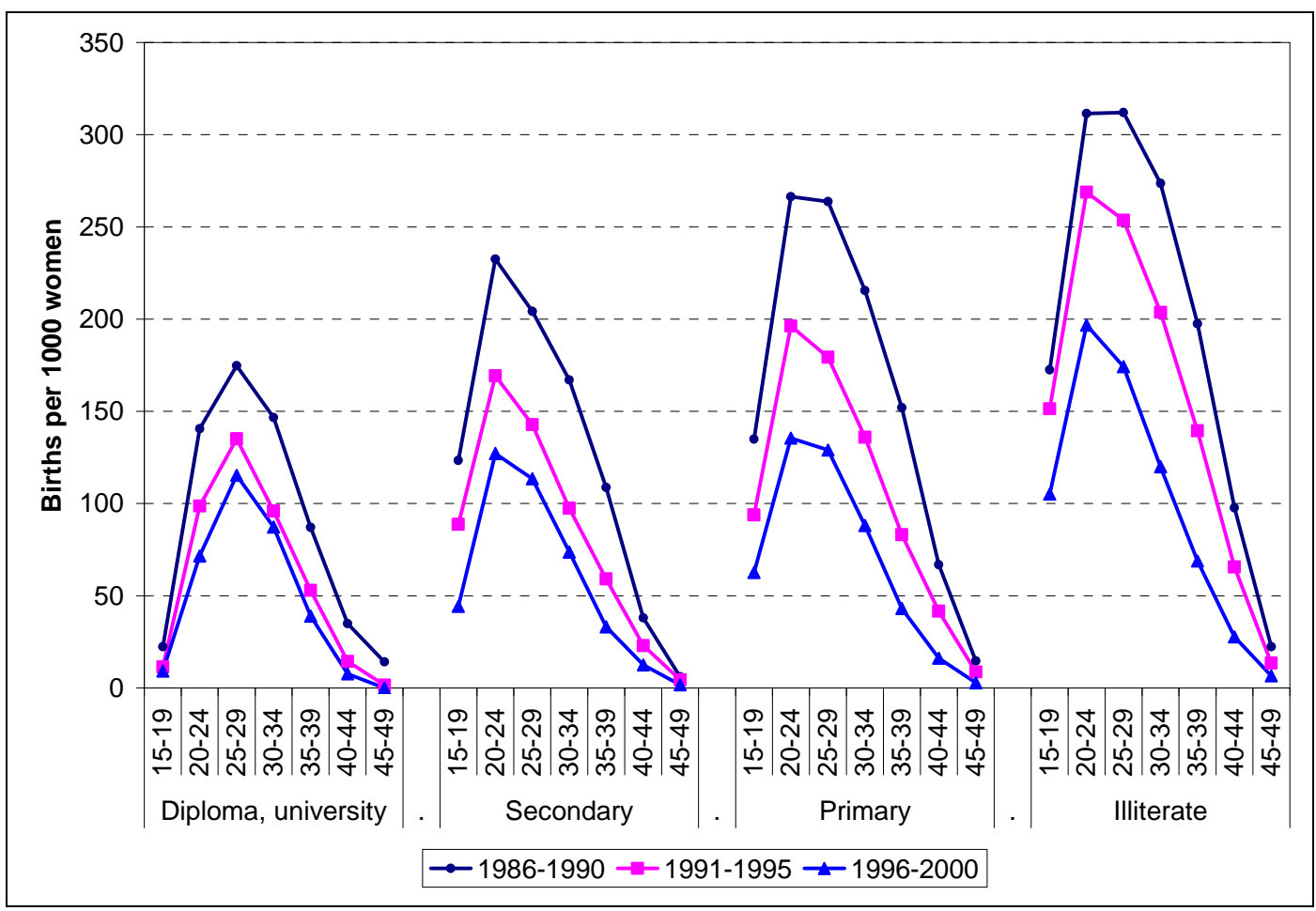

Figure 5. Own-children estimates of age-specific fertility rates by level of education during the periods 1986-1990, 1991-1995, and 1996-2000. The figures are estimated from the IDHS using the own-children method.

As the analysis above indicates, the astonishing speed of fertility decline in Iran has resulted from a combination of a rapid increase in the education of women of childbearing ages as well as significant fertility declines within educational categories. Abbasi-Shavazi et al. (2008a) attempt to decompose the overall fertility decline and assess the relative importance of these two factors. In particular they try to estimate the relative strength of two forces: 1 ) Fertility decline due to behavioral changes of women in the same educational group (e.g., decline of fertility among women with tertiary education); and 2) fertility decline due to the improving educational composition of the population (e.g., an increasing proportion of all women having tertiary education which is associated with lower fertility). They do so by conducting a simple counterfactual projection from 1980 to 2005. Observed TFR declined from 6.96 in 1980 to 1.90 in 2005. The decomposition exercise is based on applying the education- and age-specific fertility rates (EASFR) of 1980 to the education and age structure of women in subsequent years. The latter is based on the reconstructed educational attainment structures as described in the previous section. For 1980 this yields by definition the same TFR as the empirically given TFR. As a result of applying the 1980 fertility rates (EASFR) to a changed education composition of the female population, in 1985 the TFR yields a somewhat lower overall TFR of 6.57 because there are already more educated women who have lower fertility. Continuing this exercise to the year 2005 yields a TFR of 5.16 resulting from an application of the constant 1980 EASFs to the education structure of women in 2005. This implies that a TFR decline of 1.80 (6.96 5.16) can be attributed exclusively to the improving educational composition of the 
female population. Since the TFR actually declined by 5.06 (from 6.96 to 1.90), the rest of the decline must be due to declines in education-specific fertility rates. Since 1.80 is 36 percent of 5.06, one can conclude that under this approach a bit more than one-third of the total fertility decline has been due to improvements in female education, and less than two-thirds due to fertility declines within groups of the same educational attainment.

But the two-thirds of fertility decline that cannot be directly explained by the changing relative sizes of the four educational categories can in part be related to other aspects of education. First, even in terms of formal education, within each of the four categories, women improved their average education over time (higher mean years of schooling per category) which is likely to be associated with lower fertility and is not reflected in the decomposition described above. Second and more important, there are many channels of informal education and learning that contribute to value changes, changes in desired family size, more information and better access to family planning, and hence, directly or indirectly contribute to fertility decline. There is also reason to assume that the declining overall level of fertility, which is a consequence of improving education, also changes the fertility norms within the lower educational categories. These more indirect education effects are difficult to disentangle from the effects of improved family planning and reproductive health services. But in sum, there is no doubt that the world's record fertility decline in Iran was due to the combined and mutually reinforcing effects of rapidly increasing female education and the most efficient delivery of reproductive health services in a country considered to be one of the most pronouncedly Islamic in the world.

\section{Global Trends in Education, Fertility Decline and Democracy}

In this section we will return to the global level and statistically analyze on the basis of time series for 115 countries for the period 1970-2000 the association between improvements in male and female education, recent fertility declines and selected other socio-economic variables on the one hand, and improvements in quantitative indicators of democracy on the other. The democracy variable is the Freedom House index of political rights (Freedom House 2006), which summarizes information about the electoral system, political participation, corruption and accountability of the government. The original variable has seven categories. We normalized the index to lie in the $[0,1]$ interval, with higher values implying more democratic regimes. Of the 120 countries for which the above described education reconstruction has been done, this democracy index is available for 115 for the time period under construction.

Previous empirical analyses of the effects of education on democracy lend support to a positive relationship between these two variables when one exploits differences across countries. Barro (1996), Przeworski et al. (2000) and Glaeser et al. (2007) are just some examples of panel and cross-country studies that find a positive effect of education on the level of democracy by exploiting primarily differences across countries.

Using our data, Figure 6 gives a simple scatterplot showing the average level of democracy (as measured by the political rights index) against the mean years of schooling from the IIASA data for 115 countries averaged over the period 1970-2000 
for both variables. It reveals a clear and statistically significant positive relationship in which countries with more education tend to have a higher index of political rights. The picture is a bit distorted by the fact that a sizeable group of modern democracies is at the ceiling of the index at 1.0, which results in the horizontal line at the top. Without this ceiling in the democracy data the statistical correlation would be even stronger.

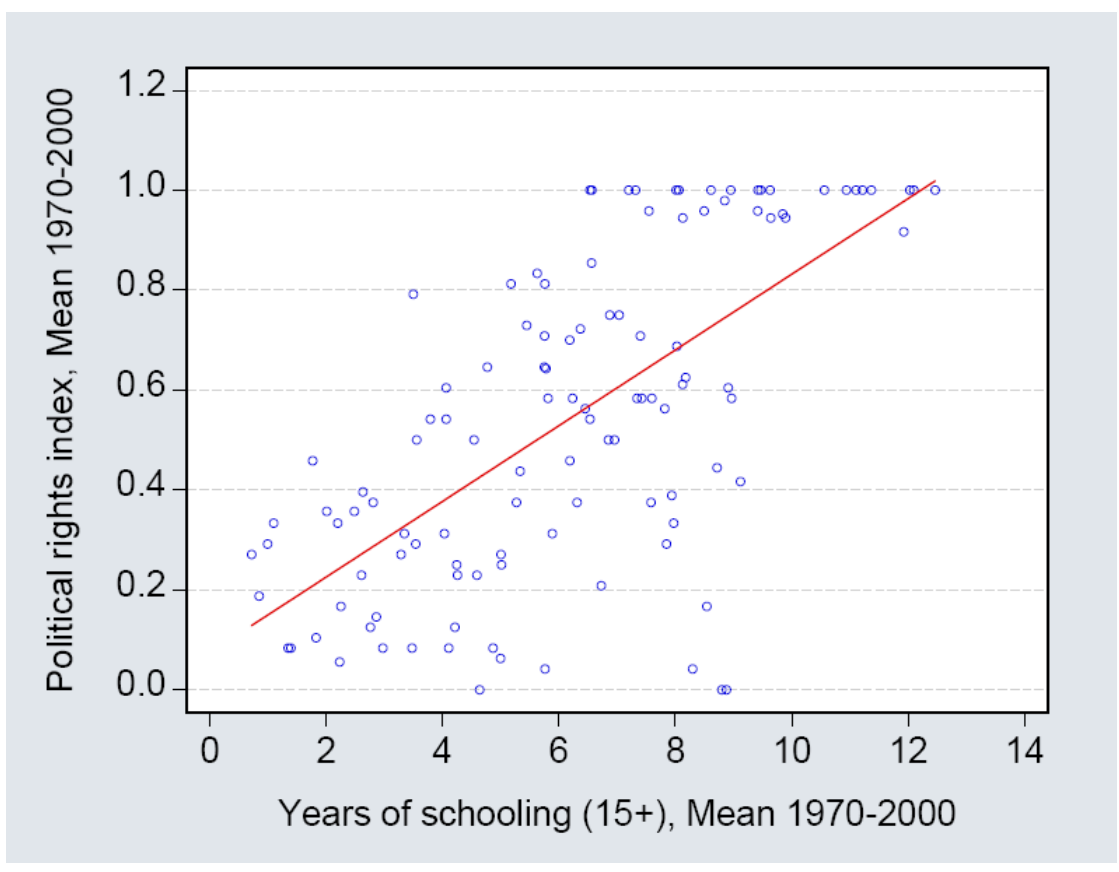

Figure 6. Average years of schooling versus democracy index.

As to the association between the dynamics of education and democracy within countries over time, the empirical findings of previous studies have been more mixed. Using a dynamic panel data model estimated using the Arellano-Bond Generalized Method of Moments (GMM) method (Arellano and Bond 1991), Acemoglu et al. (2005) do not find any significant effect of education changes on the subsequent level of democracy. Bobba and Coviello (2007) criticize the estimation method in Acemoglu et al. (2005) and show that changes in education cause changes in democracy using the Blundell-Bond "system" GMM estimator (Blundell and Bond 1998) on the same data and econometric model as Acemoglu et al. (2005).

Figure 7 shows the simple bivariate relationship between the deviations from the country means in both the education and democracy indicators. Each observation refers to a country in a five-year interval for the period 1970-2000. This is a good way of depicting the association of the two variables over time within countries. The resulting regression line is positively sloped and statistically significant. As shown in Figure 7, the horizontal line at zero refers to the democracies that have been at their maximum level of 1.0 throughout the period even though their average education continued to improve over time. Again, one would assume that without this ceiling effect the positive statistical association would be even stronger. But the purpose of these first two scatterplots was to simply present the dataset that is being used in terms of descriptive 
statistics and overall unconditional correlations. In the following we will study the data using more sophisticated econometric methods which also take advantage of the age and sex distributions of our education data.

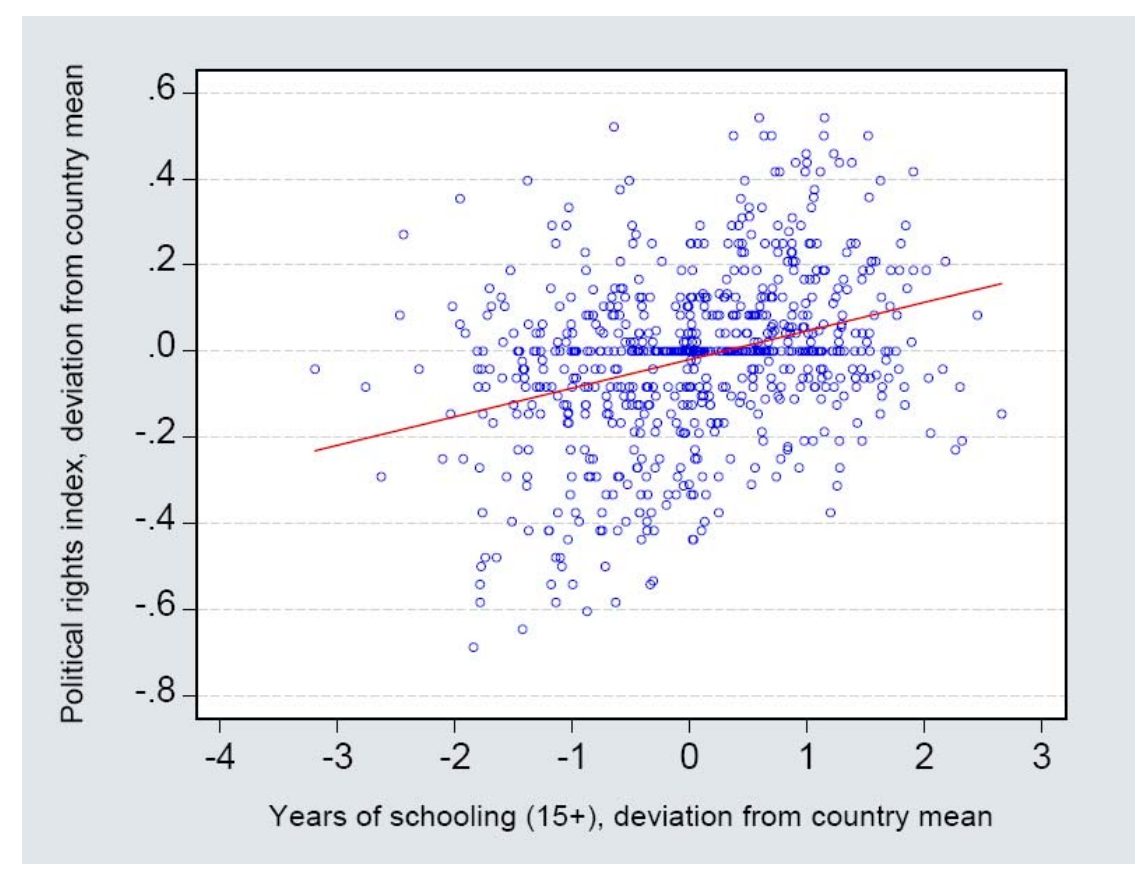

Figure 7. Average years of schooling versus democracy index: Deviations from country-specific means.

Moving to multivariate analysis, we first look at a more conventional specification of the relationship that does not take advantage of the age and gender distribution of education. The basic specification of the simplest model used to analyze the link between education and democracy within countries is given by

$$
\begin{aligned}
\operatorname{Dem}_{i, t} & =\rho \operatorname{Dem}_{i, t-1}+\theta \mathrm{E} d_{i, t-1}+\varepsilon_{i, t}, \\
\varepsilon_{i, t} & =\mu_{i}+\lambda_{t}+v_{i, t},
\end{aligned}
$$

where $D e m_{i, t}$ is the democracy variable for country $i$ at time $t,{ }^{2} E d_{i, t}$ is the education measure and $\mu_{i}$ and $\lambda_{t}$ are, respectively, country-specific and fixed time effects. This specification has become standard in the recent literature on the education-democracy link (see Acemoglu et al. 2005; Bobba and Coviello 2007; or Castelló-Climent 2008). The persistent nature of political regimes is modeled through the autoregressive term in Eq. (1), and, by controlling for all time invariant country-specific characteristics in Eq. (2), we concentrate on the effect of within-country variations of education on democracy. The education measure enters the specification in lagged form, so as to avoid simultaneity and to further enhance a causal structure between the two variables.

\footnotetext{
${ }^{2}$ Notice that a period in this specification refers to a five-year interval in our dataset.
} 
It is worth noting at this point that the ubiquitous problem of simultaneity is less important in the case of studying the effects of improving human capital on economic growth, democracy or other longer term returns to education because of a very clear temporal sequence of events. Education typically takes place at a young age and it is only with a substantial lag of more than a decade (depending on the level of education under consideration) that the better educated young adults then enter the labor force and can be expected to make a difference in terms of productivity. Hence any change in the dependent variable (be it economic growth or democracy) cannot affect the educational attainment level of the adult population at that point in time. If improvements in democracy should indeed lead to more investments in education, this can at best affect the school enrolment rates among children in the current or subsequent period which only many years later would affect the attainment level of those above age 25 . In the case of higher education this lag between investment and possible effect is shorter because the age at which people are educated is higher. For this reason we introduced an additional lag in the specification of the model as defined in Eq. (2).

The specification above is a dynamic panel model, which needs to be estimated using GMM estimators, since the usual assumption of lack of correlation between the regressors and the error term is not fulfilled due to the presence of cross-sectional fixed effects. The Arellano-Bond estimator (Arellano and Bond 1991) uses lagged levels of the dependent variable to instrument the endogenous variable in a first-differenced version of model (1)-(2). The highly persistent nature of the variables in the model, however, makes the Arellano-Bond estimator a suboptimal choice for the estimation of the model (see Blundell and Bond 1998). The system-GMM estimator proposed by Blundell and Bond (1998) has therefore become the natural technique to estimate the model above (see Bobba and Coviello 2007; Castelló-Climent 2008).

The results in Table 3 support the view that increases in educational attainment lead to improvements in the quality of democratic institutions concerning political rights. We present results based on average years of schooling for an individual above 15 years of age, as well as individual results for male and female education (also aggregated across age groups over 15). The results of this first set of estimations do not show significant quantitative differences in the effect of changes in female versus male education on changes in democracy. In both cases there is, however, a highly significant positive effect of education on the democracy measure. The estimates indicate that, on average, an increase of one year of educational attainment leads to an increase of roughly 0.05 points in the democracy index. 
Table 3. Estimation results: Democracy and average educational attainment.

\begin{tabular}{llll}
\hline \hline & $\begin{array}{l}E d_{i, t}: \text { Average years of } \\
\text { schooling (male and } \\
\text { female) }\end{array}$ & $\begin{array}{l}E d_{i, t}: \text { Average years of } \\
\text { schooling (male) }\end{array}$ & $\begin{array}{l}E d_{i, t} \text { : Average years of } \\
\text { schooling (female) }\end{array}$ \\
\hline $\operatorname{Dem}_{i, t-1}$ & $0.581^{* * *}(0.092)$ & $0.580^{* * *}(0.091)$ & $0.583^{* * *}(0.093)$ \\
$E d_{i, t-1}$ & $0.048^{* * *}(0.015)$ & $0.045^{* * *}(0.011)$ & $0.043^{* * *}(0.017)$ \\
\hline Obs. & 706 & 706 & 706 \\
Countries & 114 & 114 & 114 \\
Period effects & Yes & Yes & Yes \\
\hline AR(1) p-val. & 0.000 & 0.000 & 0.000 \\
AR(2) p-val. & 0.678 & 0.459 & 0.456 \\
Sargan p-val. & 0.002 & 0.002 & 0.001 \\
\hline \hline
\end{tabular}

\begin{abstract}
*** indicates significance at the 1 percent level. Estimation by Generalized Method of Moments system. Dependent variable is the Freedom House Political Rights Index defined in the [0,1] interval. Robust standard errors in parentheses. AR(1) and AR(2) refer to the p-value test statistic for first and second order autocorrelation on the disturbances of the first differences equations. Sargan is the p-value of the test statistic for the validity of the overidentifying restriction.
\end{abstract}

In the following we will further expand the analysis to exploit the demographic dimension of the education data in order to shed more light on the relationship between improving education and democracy. The IIASA-VID dataset described in Section 2 above allows us to evaluate the differential effect of educational attainment depending on its distribution across age groups. We use principal components analysis to reduce the dimension of the dataset on the demographic structure of education attainment and obtain three interpretable components which can be used in regressions to shed a light on the interactions between age, gender and education on the one side and democracy on the other.

The IIASA-VID dataset provides educational attainment measures for five-year age groups. Obviously, including all these variables in the specification above would lead to an overparametrized model with highly collinear covariates. Simple methods can be used in order to reduce the dimension of the dataset, such as principal component analysis.

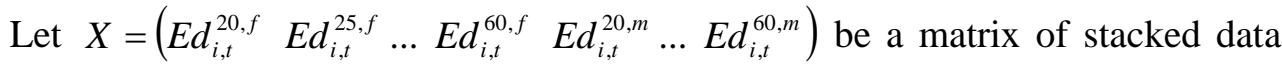
on average years of education for different age groups and both sexes, where $E d_{i, t}^{a, s}$ denotes the average years of education of an individual of gender $s$ ( $f$ is female, $m$ is male) in the age group $(a, a+5)$. Similarly, let $\Sigma=E\left[(X-E(X))(X-E(X))^{\prime}\right]$ be the variance-covariance matrix of $X$ and let $e_{j}$ and $l_{j}$ be the $j$ th eigenvector and $j$ th eigenvalue of $\Sigma$, respectively. The eigenvectors form an orthogonal basis of the data, 
and by considering them from largest to smallest we can reduce the dimension of the data using a projection of the original data on the subspace spanned by the first $L$ eigenvectors, $\tilde{X}=\Xi_{L}^{\prime} X+\phi_{X}$, where $\Xi_{L}$ is a matrix formed by the first $L$ eigenvectors of $\Sigma$ in rows and $\phi_{X}$ is the sample estimate of $E(X)$.

Table 4 presents the loadings corresponding to each of the education measures for the first three factors estimated on the data of education by age group and gender. Table 4 also gives the corresponding eigenvalues and the (cumulative) proportion of the total variance explained by the factors. The three first components explain almost 99 percent of the variance in the original data, and the resulting component loadings can be easily interpreted. The first component assigns practically equal weights to all education measures by age and gender, and thus will be interpreted as the Total education (TotEd) factor, which summarizes overall movements in the full distribution of education across age groups and genders. This factor alone explains most of the variance in the dataset, mainly due to the importance of cross-country differences in the dispersion of education measures in the panel. The second factor, which we will dub the Older age group (OldEd) factor, assigns increasingly positive loadings to the older age groups (both for males and females) and negative loadings to the younger groups. The factor summarizes the developments in the distribution of education attainment across age groups, independently of its distribution between genders. It is the third factor that summarizes the differences across genders, by assigning positive loadings to female education groups and negative loadings to male education groups. We will thus name this component the Female education (FemEd) factor. The inclusion of these factors in the specification of the democracy index allows us to study the effects of changes in the age/gender structure of education in a given country on democratization processes. 
Table 4. Principal components and loadings: Years of education dataset.

\begin{tabular}{llll}
\hline \hline & \multicolumn{3}{c}{ Factor loadings } \\
\hline & First component & Second component & Third component \\
\hline$E d^{20, m}$ & 0.2256 & -0.3803 & -0.0863 \\
$E d^{25, m}$ & 0.2318 & -0.3209 & -0.1122 \\
$E d^{30, m}$ & 0.2356 & -0.2584 & -0.1441 \\
$E d^{35, m}$ & 0.2385 & -0.1808 & -0.1866 \\
$E d^{40, m}$ & 0.2402 & -0.0889 & -0.2356 \\
$E d^{45, m}$ & 0.2406 & 0.0119 & -0.2829 \\
$E d^{50, m}$ & 0.2395 & 0.1108 & -0.311 \\
$E d^{55, m}$ & 0.237 & 0.1974 & -0.3241 \\
$E d^{60, m}$ & 0.2332 & 0.2681 & -0.3244 \\
$E d^{20, f}$ & 0.232 & -0.2905 & 0.2718 \\
$E d^{25, f}$ & 0.2371 & -0.2029 & 0.2844 \\
$E d^{30, f}$ & 0.2395 & -0.1144 & 0.2847 \\
$E d^{35, f}$ & 0.2406 & -0.019 & 0.2702 \\
$E d^{40, f}$ & 0.2403 & 0.0826 & 0.2455 \\
$E d^{45, f}$ & 0.2386 & 0.1837 & 0.214 \\
$E d^{50, f}$ & 0.2353 & 0.2719 & 0.1818 \\
$E d^{55, f}$ & 0.2309 & 0.3411 & 0.146 \\
$E d^{60, f}$ & 0.2255 & 0.3897 & 0.112 \\
\hline Eigenvalue & 16.874 & 0.7553 & 0.1690 \\
$\%$ exp. var. & 0.9374 & 0.9794 & 0.9888 \\
\hline Std. dev. & 4.1078 & 0.8691 & 0.4112 \\
Min. & -7.4393 & -2.7521 & -1.0796 \\
Max. & 8.6385 & 1.9811 & 1.115 \\
\hline \hline & & &
\end{tabular}

Using these three factors to summarize the age and gender structure of educational attainment in a given year, Eq. (3) below gives our main model where the first column of Table 5 presents the estimates of the model including the lagged factors as explanatory variables. The model which is estimated is thus

$$
\operatorname{Dem}_{i, t}=\rho \operatorname{Dem}_{i, t-1}+\theta_{1} \operatorname{TotEd}_{i, t-1}+\theta_{2} \operatorname{OldEd}_{i, t-1}+\theta_{3} \text { FemEd }_{i, t-1}+\varepsilon_{i, t} \text {, }
$$

with the error term defined as in Eq. (2). The factors have been normalized to have unit variance, and the model has been estimated using the system GMM estimator. The statistics of this basic model do not present any evidence of misspecification and the estimated parameters indicate that countries where increases in total education were coupled with an asymmetric development in the educational female-male gap favoring female education increased the democracy index more than those where the development was homogeneous or biased towards male education. The persistent nature of political regimes is captured by the significant autoregressive term in the estimated models. We also estimated the model using interactions of the factors, but these did not 
appear significant, while not affecting the estimates of the linear part of the specification. ${ }^{3}$

The rest of Table 5 presents the estimates of specifications for which other potential determinants of democracy are controlled. We alternatively control for GDP per capita $(G D P p c)$, the investment rate (Inv), life expectancy (LifeExp), the urbanization rate $(U r b)$, the share of agricultural output on total output (Agric), and the change in the young-age dependency ratio ( $\triangle A g e D e p)$.

Table 5. Estimation results: Democracy and education.

\begin{tabular}{|c|c|c|c|c|c|c|c|}
\hline $\operatorname{Dem}_{i, t-1}$ & $0.553 * * *(0.0810)$ & $0.519 * * *(0.0779)$ & $0.542^{* * *}(0.0690)$ & $0.613 * * *(0.0645)$ & $0.535 * * *(0.0773)$ & $0.551 * * *(0.0773)$ & $0.546 * * *(0.0746)$ \\
\hline $\operatorname{TotEd}_{i, t-1}$ & $0.0959^{* * *}(0.0198)$ & $0.111^{* * *}(0.0223)$ & $0.0952 * * *(0.0207)$ & $0.0941 * * *(0.0332)$ & $0.0399(0.0331)$ & $0.0946^{* * *}(0.0199)$ & $0.0882^{* * *}(0.0201)$ \\
\hline OldEd $_{i, t-1}$ & $0.0178(0.0118)$ & $0.015(0.0112)$ & $0.0291 * *(0.0123)$ & $0.0219 *(0.0122)$ & $0.0351^{* *}(0.0170)$ & $0.0204 *(0.0120)$ & $0.0259^{* *}(0.0127)$ \\
\hline FemEd $_{i, t-1}$ & $0.0570 * *(0.0234)$ & $0.0526 * *(0.0218)$ & $0.0468 * *(0.0220)$ & $0.0581^{* * *}(0.0203)$ & $0.0488 * *(0.0245)$ & $0.0648 * * *(0.0219)$ & $0.0798 * * *(0.0245)$ \\
\hline$G D P p c_{i, t-1}$ & - & $0.00763(0.0182)$ & - & - & - & - & - \\
\hline $\operatorname{Inv} v_{i, t-1}$ & - & - & $0.342 *(0.197)$ & - & - & - & - \\
\hline LifeExp $_{i, t-1}$ & - & - & - & $0.0607(0.282)$ & - & - & - \\
\hline Urban $_{i, t-1}$ & - & - & - & - & $0.388 *(0.199)$ & - & - \\
\hline Agric $_{i, t-1}$ & - & - & - & - & - & $-0.0335(0.134)$ & - \\
\hline$\Delta$ AgeDep $_{i, t}$ & - & - & - & - & - & - & $-0.0063 * *(0.0027)$ \\
\hline Intercept & $0.240^{* * *}(0.0475)$ & $0.191(0.121)$ & $0.205^{* * *}(0.0528)$ & $0.161(0.187)$ & $0.0705(0.108)$ & $0.237^{* * *}(0.0765)$ & $0.200^{* * *}(0.0508)$ \\
\hline Obs. & 706 & 574 & 615 & 630 & 706 & 692 & 705 \\
\hline Countries & 114 & 112 & 114 & 114 & 114 & 112 & 114 \\
\hline Period effects & Yes & Yes & Yes & Yes & Yes & Yes & Yes \\
\hline AR(1) p-val. & 0.000 & 0.000 & 0.000 & 0.000 & 0.000 & 0.000 & 0.000 \\
\hline AR(2) p-val. & 0.713 & 0.682 & 0.562 & 0.873 & 0.767 & 0.746 & 0.725 \\
\hline Sargan p-val. & 0.273 & 0.137 & 0.093 & 0.002 & 0.313 & 0.478 & 0.030 \\
\hline
\end{tabular}

$*[* *](* * *)$ indicates significance at the 10 percent [5 percent] (1 percent) level. Estimation by Generalized Method of Moments system. Dependent variable is the Freedom House Political Rights Index defined in the $[0,1]$ interval. Robust standard errors in parentheses. The educational-demographic factors are normalized to have mean zero and unit variance. AR(1) and $A R(2)$ refer to the p-value test statistic for first and second order autocorrelation on the disturbances of the first differences equations. Sargan is the p-value of the test statistic for the validity of the overidentifying restriction.

The different estimated models presented in Table 5 confirm the earlier results concerning the effect of changes in the total and female education factor in the basic specification. Total education levels and the level of female education relative to male education are consistently highly significant drivers of improvements in democracy. This is a very important finding in terms of its general political implications. It lends convincing statistical support to the hypothesis that improving education is a key driver of democratization around the world. High education is not necessarily a sufficient reason for democratization, but it makes a higher degree of democratic rights statistically much more likely. It is equally noteworthy that female education in particular plays a key role in changes toward more democracy. There seems to be something about the role of women in shaping basic socio-political attitudes and

\footnotetext{
${ }^{3}$ The results are available from the authors upon request.
} 
enabling societies for more civil liberties that makes their improving education particularly important for democracy. These highly significant and quantitative findings suggest the need for more qualitative research about the precise mechanisms of the specific female contribution to democratization.

With respect to the age dimension, the factor measuring the old-young education differential appears to be positively related to democratization, indicating that countries where the older cohorts tend to become more educated than the younger ones, increase their democracy index more than those dominated by higher differential education increases in young age groups. This is a plausible finding in terms of the fact that politically decisive elites in almost every country are predominantly above the age of 40-45, which is the cut-off point as indicated by Table 4. Hence the findings show that a rapid improvement of the average education of this age group is particularly relevant for successful moves towards more democracy. From a pro-democracy perspective, this is good news for countries that have a longer tradition of investing in education and implies that in countries where the education expansion is more recent, one may have to wait a little longer for the better educated cohorts to reach the ages over 40-45. This is in interesting contrast to the findings with respect to economic growth (see Lutz et al. 2008) where it is primarily the rapid increase of the better-educated young adults that makes the difference in developing countries. Hence, this may also imply that some of the recent economic star performers from tiny Singapore to giant China, where economic growth was clearly driven by the rapidly improving education in the younger labor force, may also be on the path to more democracy as the well-educated cohorts move to higher ages. This projection is, of course, under the caveat that education is only one among several relevant factors, although it might be the most important one in the longer run.

As to the other social and economic factors considered in the further columns of Table 5, the most significant and most interesting from a demographic perspective is the factor capturing changes in the young-age dependency ratio (last column of Table 5). Its negative sign indicates that declines in youth dependency tend to enhance the move toward more democracy. In other words, recent fertility declines are a factor that independently contributes to democratization even when controlling for the highly significant positive effects of all three education factors considered. This seems to imply that the demographic bonus resulting from a fertility decline (Bloom et al. 2000) exists not only with respect to enhancing economic growth. It may also be a bonus in terms of enhancing democracy.

Finally, with respect to the other social and economic factors considered in Table 5, the most significant result is that they are not significant. While the investment rate and urbanization have some weakly significant positive effects, the favorite democracy determinant of many economists, GDP per capita, turns out to be entirely insignificant after controlling for education. This also suggests that studies that claim to find an effect of income on democracy may actually be picking up the effect of education which is the more important underlying driver.

To further test the robustness of our empirical findings we repeated the entire estimation using a different democracy indicator, namely the combined polity score (Polity2 indicator) sourced from the Polity IV project (Marshall and Jaggers 2005). The results with respect to this very different independent measurement of democracy were 
stunningly similar concerning the effect of the education factors as presented in Table 5. Further robustness exercises were carried out using alternative specifications concerning the choice of covariates. The results in all cases reinforce the evidence concerning the fact that, after controlling for other economic and demographic variables, general improvements in educational attainment and in particular, those reducing the female/male attainment gap, precede democratization processes in this most comprehensive empirical panel of 115 countries since 1970.

\section{Outlook, Summary and Discussion: Female Education, Fertility Decline and Future Democracy in Iran}

In this concluding section we will make a bold attempt at applying the estimates described above with regard to the effects of education and demographic factors on democratization to make a probabilistic statement about the likely future of democracy in Iran. These projections are based on an application of the estimated model parameters to the population projections by age, sex and level of education for Iran (as described in Section 2 above) and are given in Figure 8. It shows a significant upward trend of the projection line as well as of the lines giving two standard deviations up and down. In other words, this projection indicates that there is a high probability that Iran will soon see significant increases in its political rights indicator.

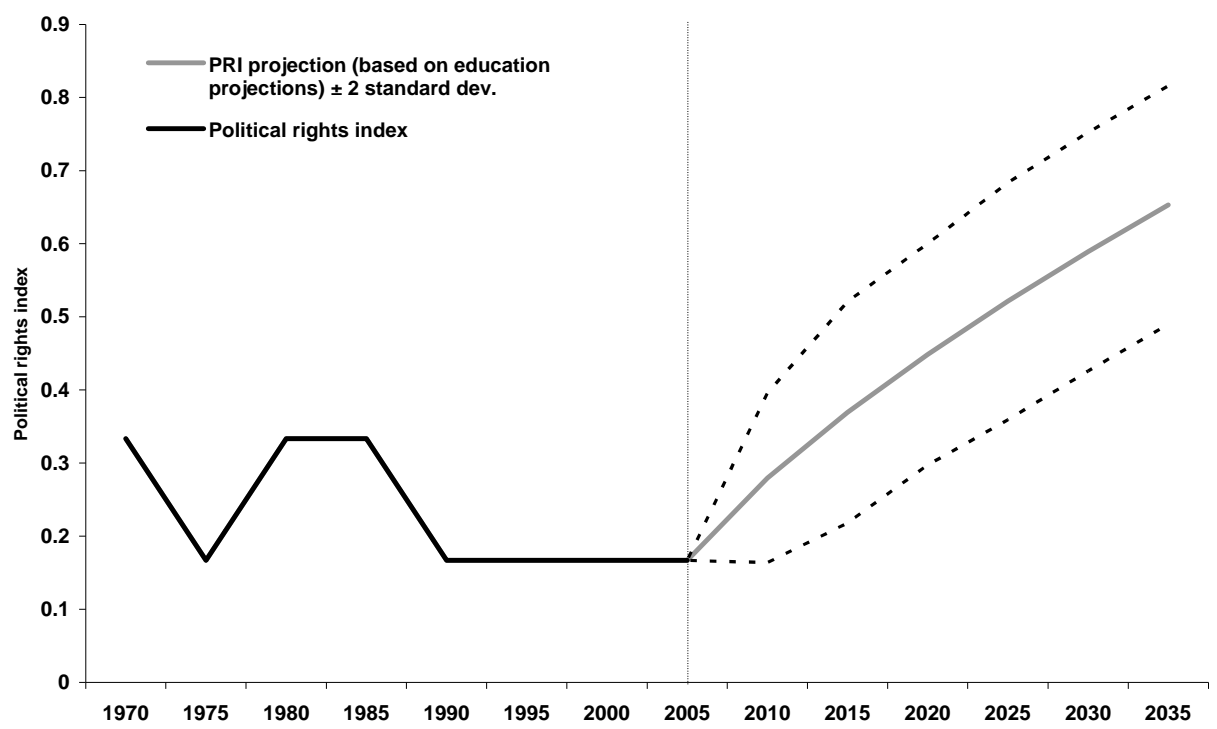

Figure 8. Political Rights Index in Iran, data and projection.

The Islamic Republic of Iran is considered one of the world's most pronounced Islamic states, yet over recent years it has seen massive improvements in female education and its fertility rate has declined from 7.0 children in 1980 to 1.9 today. This world record in fertility decline together with the emphasis on female education and the resulting modernization of gender roles - so far still mostly restricted to the private sphere - challenges many stereotypes about the effects of different religions on fertility 
and the status of women. Moreover, if the collective experience of countries around the world over the past 35 years is any guidance, these social transformations and in particular the strong increase in female education in Iran are powerful forces towards more democratic rights in the future. How could this happen and how can we arrive at such a conclusion?

After the Islamic revolution in 1979 one of the changes implemented by the new religious leadership of the country was to disband the modest beginnings of a modern family planning system. Particularly due to the taxing war with Iraq there was a strong sense that many young men were needed for the country. As a consequence the fertility rate that already had declined slightly from 7.0 in 1966 to 6.5 in 1976 went back up to around 7.0 in the early 1980s. It is remarkable that even urban fertility was close to 6.0 children during those years, with rural fertility being substantially higher. Around 1989 a major policy reversal took place that remained largely unrecognized in the West. The religious leadership was convinced by its expert advisors that after the end of the war with Iraq and with massive youth unemployment, lower fertility would be in the interest of the country (see Abbasi-Shavazi et al. 2002; Hoodfar and Assadpour 2000; Aghajanian and Mehryar 1999; Mehryar 2005). In this context it is also important to understand that unlike Roman Catholic doctrine, which is strictly anti contraception, according to Islamic teachings, couples should only have as many children as they can afford (see Musallam 1983). The leadership also recognized that rapid population growth endangered the government's ambitious efforts for universal primary and junior secondary education of both boys and girls. What followed was a well planned and apparently very efficient integration of - to the best of our knowledge - strictly voluntary family planning services into the already existing dense network of local health care facilities.

There are multiple independent empirical confirmations of this breakneck fertility decline as well as of the associated rapid increase in education. While the vital registration system in Iran tends to be incomplete, the decadal censuses are considered a reliable source of information and provided the basis for a consistent reconstruction of age-specific fertility rates since 1976 (Abbasi-Shavazi and McDonald 2006) and of the changing educational composition. Independent surveys, such as the Iran Fertility Survey and the Iran Demographic and Health Survey, as well as in-depth surveys (Iran Fertility Transition Survey and Iran Low Fertility Survey) in a number of low fertility provinces have confirmed this pattern.

These policy changes coincided with a remarkable increase in the educational level of younger women in Iran, particularly in rural areas. While the census of 1976 shows that only 10 percent of rural women aged 20-24 were literate, this rate increased to 37 percent in 1986, 78 percent in 1996 and 91 percent in 2006. Over this period the number of women in this age group grew very rapidly - roughly by a factor of three. Due to very high past fertility, this expansion in literacy is even more remarkable. It was only possible by complementing the expansion of school enrolment with a rare adult literacy campaign which began right after the revolution in 1979.

In terms of formal education, the improvements are no less impressive, particularly the increase of young women with secondary and higher education, as shown in Figure 1. In 1970 some 260,000 women aged 20-29 had secondary or higher education; by 2005 this number had increased more than 18-fold to 4.80 million. By 
2015 it is expected to increase further to almost 6 million, before the absolute numbers of women in this age group start to decline due to the sharp fertility decline described above. The proportions of young women with higher education will continue to increase substantially. At the lower end of the education spectrum, young women without any formal education, who were still the largest category in 1975 comprising more than half of all young women, have been steadily declining to a mere 6 percent in 2005.

In many African and some Arab countries, comparably high levels of population growth have resulted in increasing numbers of uneducated women despite efforts to improve school enrolment and significant international assistance in this task. Against this background, the successful Iranian uphill battle to improve education in spite of exploding numbers of youngsters and without international assistance must be viewed as a major achievement in human development.

It is important to note that fertility decline and female education reinforce each other: more educated women tend to have fewer children and relatively fewer children make it easier to increase enrolment rates. This major transformation in the social structure of Iran brought about by the combined forces of a rapidly changing age composition due to the precipitous fertility decline and massive improvements in the education of both men and women will in all likelihood affect the economic growth potential, social and political institutions and - as the results in the previous section show - present a force towards more democratic rights.

Figure 8 presents the historical data on the chosen Freedom House indicator of political rights together with projections based on our econometric model. For the past 15 years, the democracy indicator for Iran has been lower than during the 1980s. Using the elasticities implied by the models estimated in the previous section and the projections of educational attainment by age group for Iran in the period 2005-2035 as presented earlier in this paper, we can statistically project the future development of the Political Rights Index. The result is presented in Figure 8 and corresponds to the projections based on the simplest estimated model, which specifies the democracy index as a function of the past level of democracy and the three educational-demographic factors (first column of Table 5). Including the effects of likely future urbanization and changes in the youth dependency ratio would even imply a steeper increase.

The qualitative predictions of the model are clear: the rapid improvement of education in Iran is likely to generate powerful forces towards more democratic rights in the country. Based on the quantitative analysis presented here there is a high probability that over the coming years, Iran will transform naturally into a modern democracy.

\section{References}

Abbasi-Shavazi, M.J. 2000. Effects of Marital Fertility and Nuptiality on Fertility Transition in the Islamic Republic of Iran. Working Papers in Demography, No. 84. Canberra: The Australian National University.

Abbasi-Shavazi, M.J. and P. McDonald. 2006. The fertility decline in the Islamic Republic of Iran, 1972-2000. Asian Population Studies 2(3): 217-237.

Abbasi-Shavazi, M. J., P. McDonald, and M. Hosseini-Chavoshi. Forthcoming. The Fertility Transition in Iran: Revolution and Reproduction. Berlin: Springer. 
Abbasi-Shavazi, M.J., W. Lutz, M. Hosseini-Chavoshi, and S. KC. 2008a. Education and the World's Most Rapid Fertility Decline in Iran. Interim Report IR-08-010. Laxenburg, Austria: International Institute for Applied Systems Analysis.

Abbasi-Shavazi, M.J., P. McDonald, and M. Hosseini-Chavoshi. 2008b. Modernization or cultural maintenance: The practice of consanguineous marriage in Iran. Journal of Biosocial Science 40(4): 911-933.

Abbasi-Shavazi, M.J., P. McDonald, and M. Hosseini-Chavoshi. 2003. Changes in Family, Fertility Behavior and Attitudes in Iran. Working Paper in Demography No. 88. Canberra: Australian National University.

Abbasi-Shavazi, M.J., A. Mehryar, G. Jones, and P. McDonald. 2002, Revolution, war and modernization: Population policy and fertility change in Iran. Journal of Population Research 19(1): 25-46.

Abdollahyan, H. 2004. The generation gap in contemporary Iran. Journal of Welt Trends 44: 78-85.

Acemoglu, A., S. Johnson, J. Robinson, and P. Yared. 2005. From education to democracy? American Economics Association Papers and Proceedings 95: 4449.

Agha, H. 1985. Study of Fertility in Iran and its Relation to Socio-economic Indicators based on the IFS [in Persian]. Shiraz, Iran: Population Studies Center, University of Shiraz.

Aghajanian, A. and A. Mehryar. 1999. Fertility transition in the Islamic Republic of Iran: 1967-1996. Asia-Pacific Population Journal 14(1): 21-42.

Aghajanian, A., A.B. Gross, and S.M. Lewis. 1992. Evaluation of Iran Fertility Survey. WP-93-2. Seattle: University of Washington, Center for Studies in Demography and Ecology.

Amani, M. 1996. An attempt at the historical outlook of the trends of births and death rates and study of the stage of demographic transition in Iran [in Persian]. Journal of Population 13-14: 71-83.

Amani, M. 1970. Births and Fertility in Iran, Division of Population Research [in Persian]. Tehran, Iran: Institute for Social Studies and Research, University of Tehran.

Arellano, M. and S.R. Bond. 1991. Some tests of specification for panel data: Monte Carlo evidence and an application to employment equations. Review of Economic Studies 58: 277-297.

Barro, R.J. 1996. Democracy and growth. Journal of Economic Growth 1: 1-27.

Barro, R.J. and J.W. Lee. 1996. International measures of schooling years and schooling quality. American Economic Review 86: 218-223.

Benhabib, J. and M. Spiegel. 1994. The role of human capital in economic development: Evidence from aggregate cross-country data. Journal of Monetary Economics 34: 143-173.

Bloom, D.E. 2006. Education in a globalized world. World Economics 7: 87-109. 
Bloom, D.E., D. Canning, and P. Malaney. 2000. Population dynamics and economic growth in Asia. Population and Development Review 26 (supp.): 257-290.

Blundell, R.W. and S.R. Bond. 1998. Initial conditions and moment restrictions in dynamic panel data models. Journal of Econometrics 87: 115-143.

Bobba, M. and D. Coviello. 2007. Weak instruments and weak identification in estimating the effects of education on democracy. Economics Letters 96: 301306.

Caldwell, J.C. 1989. Mass education as a determinant of mortality decline. Pages 101109 in J.C. Caldwell and G. Santow (eds), Selected Readings in the Cultural, Social and Behavioral Determinants of Health. Health Transition Series, No. 1. Canberra: Australian National University.

Caldwell, J. 1982. Theory of Fertility Decline. London: Academic Press.

Castelló-Climent, A. 2008. On the distribution of education and democracy. Journal of Development Economics 87(2): 179-190.

Cincotta, R.P. 2008. How democracies grow up. Foreign Policy 80, April/May.

Cleland, J. 1990. Maternal education and child survival: Further evidence and explanation. Pages 400-419 in J.C. Caldwell, S. Findley, P. Caldwell, G. Santow, W. Cosford, J. Braid, and D. Broers-Freeman (eds.), What We Know About Health Transition: The Cultural, Social and Behavioral Determinants of Health. Proceedings of an International Workshop, Canberra, May 1989. Health Transition Series, No. 2. Canberra: The Australian National University.

Cochrane, S.H. 1979. Fertility and Education: What Do We Really Know? Baltimore, MD: John Hopkins University Press.

Cohen, D. and M. Soto. 2007. Growth and human capital: Good data, good results. Journal of Economic Growth 12(1): 51-76.

de la Fuente, A. and R. Domenech. 2006. Human capital in growth regressions: How much difference does data quality make? Journal of the European Economic Association 4: 1-36.

Freedom House. 2006. Freedom in the World. Website and Book. Washington, DC: Freedom House.

Glaeser, E.L., G. Ponzetto, and A. Shleifer. 2007. Why does democracy need education. Journal of Economic Growth 12: 77-99.

Hoodfar, H. 1996. Bargaining with fundamentalism: Women and the politics of population control in Iran. Reproductive Health Matters 8: 30-40.

Hoodfar, H. and S. Assadpour. 2000. The politics of population policy in the Islamic Republic of Iran. Studies in Family Planning 31(1): 19-34.

Hosseini-Chavoshi, M. 2007. Fertility Regulation in Iran: An Analysis of Trends, Levels and Correlates. PhD Thesis in Demography. Canberra: Australian Demographic and Social Research Institute, The Australian National University. 
Kasarda, J.D., J.O.C. Billy, and K. West. 1986. Status Enhancement and Fertility: Reproductive Responses to Social Mobility and Educational Opportunity. Orlando, Florida: Academic Press.

KC, S., B. Barakat, A. Goujon, V. Skirbekk, and W. Lutz. 2008. Projection of Populations by Level of Educational Attainment, Age and Sex for 120 Countries for 2005-2050. Interim Report IR-08-038. Laxenburg, Austria: International Institute for Applied Systems Analysis.

Keyfitz, N. 1986. The youth cohort and Indonesian history. Masyarakat Indonesia 13(1): 1-13.

Kian-Thiebaut, A. 2002. Women and the making of civil society in post-Islamist Iran. Pages 56-73 in Eric Hooglund (ed.), Twenty Years of Islamic Revolution: Political and Social Transition in Iran since 1979. Syracuse, NY: Syracuse University Press.

Kuenzi, M. 2006. Nonformal education, political participation, and democracy: Findings from Senegal. Political Behavior 28: 1-31.

Ladier-Fouladi, M. 1997. The fertility transition in Iran. Population: An English Selection 9: 191-214.

Lipset, S.M. 1959. Some social requisites of democracy: Economic development and political legitimacy. American Political Science Review 53: 69-105.

Lucas, D., and P. Meyer. 1994. The background to fertility. Pages 56-68 in D. Lucas and P. Meyer (eds.), Beginning Population Studies. 2nd edition. Canberra: The Australian National University.

Lutz, W., J. Crespo Cuaresma, and W. Sanderson. 2008. The demography of educational attainment and economic growth. Science 319: 1047-1048.

Lutz, W., A. Goujon, S. KC, and W. Sanderson. 2007. Reconstruction of populations by age, sex and level of educational attainment for 120 countries for 1970-2000. Vienna Yearbook of Population Research 2007, pp. 193-235.Vienna, Austria: Verlag der Österreichischen Akademie der Wissenschaften.

Lutz, W., A. Goujon, and G. Doblhammer-Reiter. 1999. Demographic dimensions in forecasting: Adding education to age and sex. Pages 42-58 in W. Lutz, J.W. Vaupel, and D.A. Ahlburg (eds.), Frontiers of Population Forecasting. A Supplement to Vol. 24, 1998, Population and Development Review. New York: The Population Council.

Marshall, M.G. and K. Jaggers. 2005. Polity IV Project: Political Regime Characteristics and Transition, 1800-2004. College Park, MD, and Fairfax, VA: University of Maryland and George Mason University.

Mehryar, A. 2005. Shi'ite teachings, pragmatism and fertility change in Iran. Pages 118156 in G. Jones and M. Karim (eds.), Islam, the State and Population. London: Hurst and Co.

Ministry of Health and Medical Education. 2000. Demographic and Health Survey. Tehran, Iran: Ministry of Health and Medical Education. 
Mir-Hosseini, Z. 2002. Religious modernists and the women question. Pages 74-95 in Eric Hooglund (ed.), Twenty Years of Islamic Revolution: Political and Social Transition in Iran since 1979. Syracuse, NY: Syracuse University Press.

Mirzaie, M. 2005. Swings in fertility limitations in Iran. Critique: Critical Middle Eastern Studies 14(1): 25-33.

Musallam, B. 1983. Sex and Society in Islam. Cambridge, UK: Cambridge University Press.

Pritchett, L. 2001. Where has all the education gone? The World Bank Economic Review 15(3): 367-391.

Przeworski, A., M.E. Alvarez, J.A. Cheibub, and F. Limongi. 2000. Democracy and Development: Political Institutions and Well-being in the World, 1950-1990. New York: Cambridge University Press.

Salehi-Isfahani, D., M.J. Abbasi-Shavazi, and M. Hosseini-Chavoshi. 2009. Family Planning and Rural Fertility Decline in Iran: A Study in Program Evaluation. Paper presented at the 2009 Population Association of America Annual Meeting, April 30 to May 2, Detroit, Michigan, USA.

Shadi-Talab, J. 2005. Iranian women: Rising expectations. Critique: Critical Middle Eastern Studies 14(1): 35-55.

United Nations. 2005. World Population Prospects: The 2004 Revision. New York: United Nations, Department of Economic and Social Affairs, Population Division. 